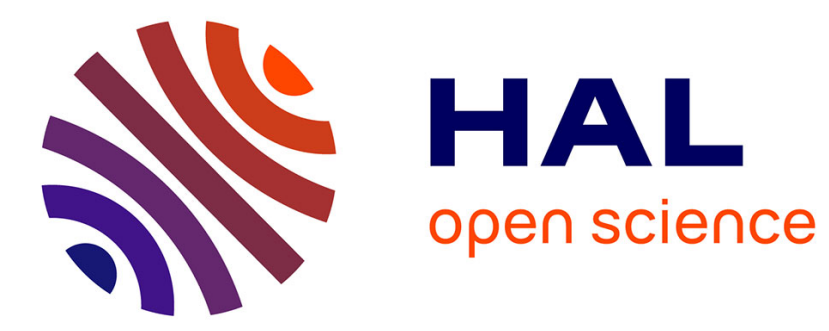

\title{
Modeling the composite hardness of multilayer coated systems
}

\author{
Eli Saúl Puchi-Cabrera, M.H. Staia, Alain Iost
}

\section{To cite this version:}

Eli Saúl Puchi-Cabrera, M.H. Staia, Alain Iost. Modeling the composite hardness of multilayer coated systems. Thin Solid Films, 2015, 578, pp.53-62. 10.1016/j.tsf.2015.01.070 . hal-01169505

\section{HAL Id: hal-01169505 \\ https://hal.science/hal-01169505}

Submitted on 29 Jun 2015

HAL is a multi-disciplinary open access archive for the deposit and dissemination of scientific research documents, whether they are published or not. The documents may come from teaching and research institutions in France or abroad, or from public or private research centers.
L'archive ouverte pluridisciplinaire HAL, est destinée au dépôt et à la diffusion de documents scientifiques de niveau recherche, publiés ou non, émanant des établissements d'enseignement et de recherche français ou étrangers, des laboratoires publics ou privés. 


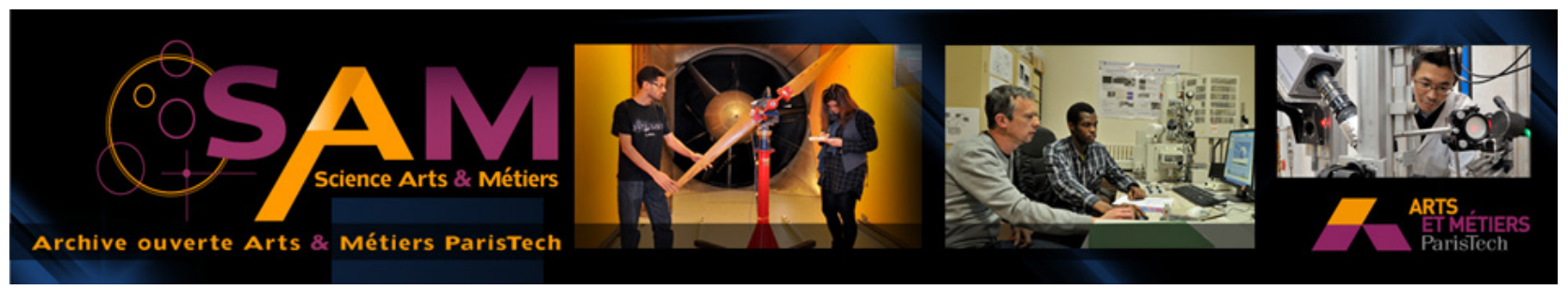

Science Arts \& Métiers (SAM)

is an open access repository that collects the work of Arts et Métiers ParisTech researchers and makes it freely available over the web where possible.

This is an author-deposited version published in: http://sam.ensam.eu

Handle ID: .http://hdl.handle.net/10985/9659

\section{To cite this version :}

E.S. PUCHI-CABRERA, M.H. STAIA, Alain IOST - Modeling the composite hardness of multilayer coated systems - Thin Solid Films - Vol. 578, p.53-62 - 2015 


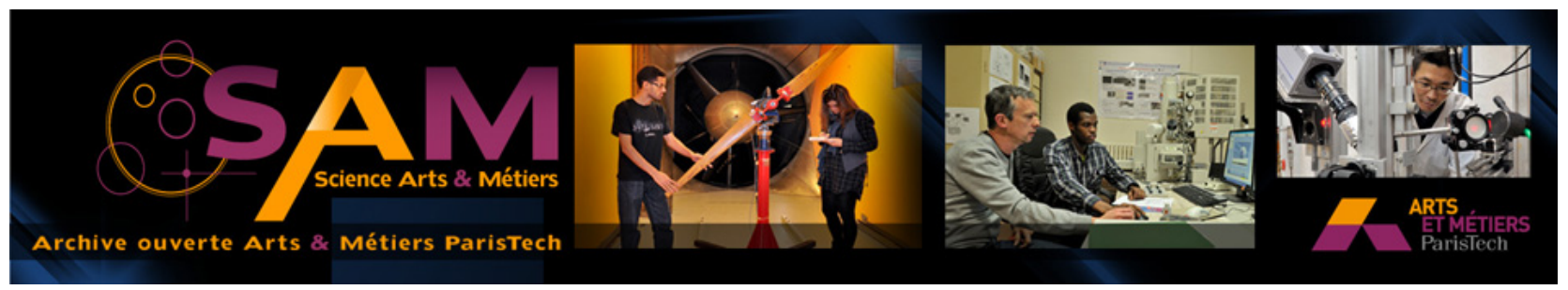

Science Arts \& Métiers (SAM)

is an open access repository that collects the work of Arts et Métiers ParisTech researchers and makes it freely available over the web where possible.

This is an author-deposited version published in: http://sam.ensam.eu Handle ID: .http://hdl.handle.net/null

\section{To cite this version :}

E.S. PUCHI CABRERA, M.H. STAIA, Alain IOST - Modeling the composite hardness of multilayer coated systems - Thin Solid Films - Vol. 578, p.53-62 - 2015 


\title{
Modeling the composite hardness of multilayer coated systems
}

\author{
E.S. Puchi-Cabrera ${ }^{\text {a,b,c,* }}$, M.H. Staia ${ }^{\text {a,b,d }}$, A. Iost $^{\text {d }}$ \\ a School of Metallurgical Engineering and Materials Science, Faculty of Engineering, Universidad Central de Venezuela, 47885 Los Chaguaramos, Caracas 1040, Venezuela \\ b Venezuelan National Academy for Engineering and Habitat, Palacio de las Academias, 1723, Caracas 1010, Venezuela \\ c Université Lille Nord de France, USTL, LML, CNRS, UMR 8107, F-59650 Villeneuve d'Ascq, France \\ d Arts et Métiers ParisTech, MSMP, Centre de Lille, 8, Boulevard Louis XIV, 59000 Lille Cedex, France
}

\section{Keywords:}

Hardness modeling

Multilayer coatings

Indentation loading response

Nanoindentation testing

\begin{abstract}
A B S T R A C T
The change in the composite hardness with penetration depth derived from nanoindentation tests conducted on coated systems, which involve the deposition of multilayer coatings, in general exhibits a complex shape, as a consequence of the sequential contribution of each coating layer to the composite hardness during indentation loading. In spite that there are a number of models, which have been proposed for describing the change of the composite hardness with penetration depth for monolayer coatings, as well as for determining the coating and substrate hardness, very few research works have addressed the problem of describing this kind of data for multilayer coatings. In the present communication, a rational approach is proposed for extending two models widely used for the analysis of monolayer coatings, in order to describe the composite hardness data of multilayer coatings, as well as for determining the hardness of each individual layer and that of the substrate. Thus, a modified form of the models earlier advanced by Korsunsky et al. and Puchi-Cabrera, as well as their computational instrumentation, are proposed. The extension of both models to deal with multilayer coatings is conducted on the basis of the model developed by lost et al., in order to adapt the Jönsson-Hogmark model to the analysis of indentation data of multilayer coatings. Such a methodology provides a means of computing the volume fraction of each individual layer in the coating, which contributes to the composite hardness. According to the results obtained, this scheme seems to be general enough to be applicable to different hardness models other than the Jönsson-Hogmark model. The proposed modified models are validated employing nanoindentation results obtained from a 2024-T6 aluminum alloy coated with a diamond-like carbon film, employing electroless NiP as intermediate layer. The advantages and disadvantages of the different models employed in the analysis are thoroughly discussed.
\end{abstract}

\section{Introduction}

In general, multilayer coatings exhibit better mechanical properties and higher chemical inertness than monolayer coatings and therefore, they are widely employed for the improvement of the surface properties of different parts and components subjected to diverse forms of surface damage, which include among others, wear, scratch, abrasion, corrosion and high temperature oxidation. In particular, the improvement in mechanical properties of multilayer coatings arises from the presence of different interlayers in their architecture, which makes possible the deflection of cracks, increasing their ability to reduce crack propagation and therefore, leading to a better performance of the coated system against damage by wear, scratch and abrasion.

\footnotetext{
* Corresponding author at: Université Lille Nord de France, USTL, LML, CNRS, UMR 8107, F-59650 Villeneuve d'Ascq, France.

E-mail addresses: Eli.Puchi@univ-lille1.fr (E.S. Puchi-Cabrera), mhstaia@gmail.com (M.H. Staia), alain.iost@ensam.eu (A. Iost).
}

Due to their outstanding properties and therefore, to the exceptional capabilities provided to the coated system, multilayer coatings have attracted a great deal of attention and in the past few years have become an important research objective. Thus, a wide range of scientific and technological aspects concerning these coatings have been investigated, which include, among others, the correlation between microstructure, mechanical properties (hardness and elastic modulus), impact resistance and tribological performance of different systems [1-10], deformation mechanisms induced by indentation and nanoindentation damage [11-13], effect of layer architecture (number of layers, layer thickness, modulation ratio, bi-layer and multi-layer period) on mechanical properties, tribological performance and oxidation resistance [14-28], extraction of mechanical properties by different methods [29, 30], effect of substrate temperature on residual stresses, hardness and resistivity [31,32] and plastic deformation and size effects [33,34].

As pointed out by Kataria et al. [35], the properties of multilayer coatings are significantly dependent on the properties of the individual layers, which compose the multilayer coating. The above observation points out the need of developing a consistent methodology for extracting the 


\begin{tabular}{|c|c|}
\hline \multicolumn{2}{|c|}{ Nomenclature } \\
\hline \multicolumn{2}{|c|}{ Arabic symbols } \\
\hline \multicolumn{2}{|c|}{$a_{f}, a_{f}^{(i)}, a_{f}^{(j)}$ volume fraction of the coating material } \\
\hline$a_{f}^{(S)}$ & volume fraction of the substrate material \\
\hline $\mathrm{B}^{(\mathrm{i})}$ & $\begin{array}{l}\text { indentation size effect parameter for the coating, } \\
\text { GPa nm }\end{array}$ \\
\hline $\mathrm{B}_{\mathrm{s}}$ & $\begin{array}{l}\text { indentation size effect parameter for the substrate, } \\
\text { GPa nm }\end{array}$ \\
\hline$C, C^{(i)}$ & constant in the Jönsson-Hogmark model \\
\hline h & penetration depth, nm \\
\hline & hardness of the fully dense material, GPa \\
\hline & composite hardness, GPa \\
\hline $\mathrm{H}_{\mathrm{f}}, \mathrm{H}_{\mathrm{f}}^{(\mathrm{i})}$ & coating hardness, GPa \\
\hline $\mathrm{H}_{\mathrm{fO}}^{(\mathrm{i})}$ & intrinsic coating hardness, GPa \\
\hline $\mathrm{H}_{\mathrm{s} 0}$ & intrinsic substrate hardness, GPa \\
\hline $\mathrm{H}_{\mathrm{s}}$ & substrate hardness, GPa \\
\hline $\mathrm{K}_{\mathrm{f}}^{(\mathrm{i})}$ & fraction of coating thickness \\
\hline $\mathrm{N}$ & number of experimental data points \\
\hline $\mathrm{N}_{\mathrm{L}}$ & number of layers in the multilayer coating \\
\hline & number of material parameters in the model \\
\hline & constant in the Korsunsky et al. models \\
\hline & constant in the Puchi-Cabrera model \\
\hline $\mathrm{t}_{\mathrm{f}}, \mathrm{t}_{\mathrm{f}}^{(\mathrm{i})}$ & coating thickness, nm \\
\hline \multicolumn{2}{|c|}{ Greek symbols } \\
\hline & constant in the Luo et al. model \\
\hline$\beta_{0}, \beta_{k}, \beta$ & (j) constants in the Korsunsky et al. model \\
\hline $\begin{array}{l}\beta_{\mathrm{p}}, \beta_{\mathrm{p}}^{(\mathrm{j})} \\
\Omega\end{array}$ & $\begin{array}{l}\text { constants in the Puchi-Cabrera model } \\
\text { sum of squares, } \mathrm{GPa}^{2}\end{array}$ \\
\hline
\end{tabular}

intrinsic properties of the different layers. As indicated recently by Bull [34], the determination of mechanical properties such as hardness, elastic modulus and fracture toughness of individual coating layers is of utmost importance for design purposes.

However, in order to accomplish this objective the influence of both the layers below and the substrate should be avoided. In the case of monolayer films deposited onto a given substrate, particularly for extracting the film intrinsic hardness, usually the rule of thumb of $10 \%$ of the coating thickness is applied. Nevertheless, this rule is not expected to be fulfilled strictly, since it depends significantly on the difference between the elastic and plastic properties of film and substrate (in the case of monolayer coatings) or between the properties of the different layers, which constitute the multilayer coating.

Multilayer coatings are quite heterogeneous materials and therefore, nanoindentation testing techniques represent the most suitable means of evaluating their global response under indentation loading, as well as assessing the mechanical properties and damage mechanisms of the individual layers. However, given the heterogeneous nature of these materials, it is expected that under indentation a complex stress state develops, as a consequence of the difference in mechanical properties between the layers, as well as between the layers and substrate and that such complex stresses have in turn an influence on the indentation response of the coated system.

Despite that a number of models have been developed for the description of the composite hardness of coatings systems, which involve the deposition of a monolayer coating [36-44], very few works have been devoted to development of similar models for the case of multilayer coatings. In this sense, one of the most significant contributions is that developed by Iost et al. [45], who modified the hardness model originally advanced by Jönsson and Hogmark [36], based on an area law of mixture. In this way, Iost and co-workers [45] were able to analyze the indentation behavior of a porous silicon structure obtained by anodization, consisting of a three-layer structure compose of a top oxidized porous silicon layer, an intermediate porous silicon layer and the silicon substrate. This approach allows the simultaneous determination of the intrinsic hardness of each of the individual layers, as well as that of the substrate. Also, it takes into consideration the behavior of each layer (plastic deformation or fracture) under indentation loading.

The original model advanced by Jönsson and Hogmark [36] for the analysis of the indentation behavior of a single coating deposited unto the substrate has a physical basis, in the sense that it stems from the proportionality that exists between the indented area and the square of the indentation depth. However, it has been criticized on the basis of the ill-definition of the volume fraction of the coating that contributes to the composite hardness and its critical dependence on coating thickness $[46,47]$.

Therefore, the present investigation has been conducted in order to develop a simple and systematic methodology leading to a similar modification of two other models widely employed in the description of the composite hardness of coated systems. These models include that advanced by Korsunsky et al. [39-41], as well as the one later proposed by Puchi-Cabrera $[42,43]$, in such a way that these models could also be employed in the analysis of the indentation behavior of multilayer coatings and particularly in the determination of the intrinsic hardness of the individual layers by taking also into consideration their behavior under indentation loading.

\section{Basis of the model}

The detailed account of the modification of the model advanced Jönsson and Hogmark [36] (JH) for the description of the composite hardness of multilayer coatings has already been given by lost et al. [45]. Therefore, in the present communication only the most relevant equations, as well as their computation instrumentation will be presented.

In the original model proposed by Jönsson and Hogmark [36], the volume fraction of the coating material, which contributes to the composite hardness, $a_{f}$, expressed in terms of indentation (penetration) depth, $h$, is given by:

$\mathrm{a}_{\mathrm{f}}=2 \frac{\mathrm{Ct}}{\mathrm{h}}-\frac{\mathrm{C}^{2} \mathrm{t}_{\mathrm{f}}^{2}}{\mathrm{~h}^{2}}=1-\left(1-\frac{\mathrm{Ct}}{\mathrm{h}}\right)^{2}$.

In the above equation $C$ represents a constant, which depends on the indentation behavior of the coating material and indenter geometry [45] and $\mathrm{t}_{\mathrm{f}}$ the coating thickness. If under indentation loading employing a Berkovich indenter the coating undergoes fracture, $C=0.0915$, whereas if the coating undergoes plastic deformation, $C=0.1746$.

Since the volume fraction of the coating material should fulfill the condition that: $0 \leq \mathrm{a}_{\mathrm{f}} \leq 1$, Eq. (1) is ill defined, since if $\mathrm{h}<\mathrm{Ct} \mathrm{t}_{\mathrm{f}} \mathrm{a}_{\mathrm{f}}$ does not tend to 1 , as it should. Thus, the above definition should be complemented in the following manner:

$$
\begin{aligned}
& \mathrm{a}_{\mathrm{f}}=1 \quad \text { if } \mathrm{h}<\mathrm{Ct}_{\mathrm{f}} \\
& a_{f}=1-\left(1-\frac{C t_{f}}{h}\right)^{2} \text { otherwise. }
\end{aligned}
$$

Thus, for a monolayer coating the composite hardness, $\mathrm{H}_{c}$, would be given by:

$\mathrm{H}_{\mathrm{c}}=\mathrm{a}_{\mathrm{f}} \mathrm{H}_{\mathrm{f}}+\left(1-\mathrm{a}_{\mathrm{f}}\right) \mathrm{H}_{\mathrm{s}}$

where, $\mathrm{H}_{\mathrm{f}}$ represents the intrinsic hardness of the coating and $\mathrm{H}_{\mathrm{s}}$ the substrate hardness. Thus, given the ill-definition of $\mathrm{a}_{\mathrm{f}}$, from the computational viewpoint, in order to determine simultaneously the values of both $\mathrm{H}_{\mathrm{f}}$ and $\mathrm{H}_{\mathrm{s}}$, the composite hardness should be defined as follows:

$$
\begin{array}{ll}
\mathrm{H}_{\mathrm{c}}=\mathrm{H}_{\mathrm{f}} & \text { if } \mathrm{h}<\mathrm{Ct}_{\mathrm{f}} \\
\mathrm{H}_{\mathrm{c}}=\mathrm{a}_{\mathrm{f}} \mathrm{H}_{\mathrm{f}}+\left(1-\mathrm{a}_{\mathrm{f}}\right) \mathrm{H}_{\mathrm{s}} & \text { otherwise. }
\end{array}
$$


In the case of a multilayer coating composed of $\mathrm{N}_{\mathrm{L}}$ layers the computational procedure would involve the following steps. For the first layer, the volume fraction of coating which contributes to the composite hardness would be given by:

$$
\begin{array}{ll}
\mathrm{a}_{\mathrm{f}}{ }^{(1)}=1 & \text { if } \mathrm{h}<\mathrm{C}^{(1)} \\
\left.\mathrm{a}_{\mathrm{f}}{ }^{(1)}=1-1-\frac{\mathrm{C}^{(1)} \mathrm{t}_{\mathrm{f}}{ }^{(1)}}{\mathrm{h}}\right)^{2} & \text { otherwise. }
\end{array}
$$

Whereas, for the jth layer of the coating:

$$
\begin{aligned}
& \mathrm{a}_{\mathrm{f}}^{(\mathrm{j})}=1-\sum_{\mathrm{i}=1}^{\mathrm{j}-1} \mathrm{a}_{\mathrm{f}}^{(\mathrm{i})} \\
& \mathrm{a}_{\mathrm{f}}^{(\mathrm{j})}=\left\{1-\left[1-\frac{\sum_{\mathrm{i}=1}^{\mathrm{j}} \mathrm{c}^{(\mathrm{i})} \mathrm{t}_{\mathrm{f}}^{(\mathrm{i})}}{\mathrm{h}}\right]^{2}\right\}-\left\{1-\left[1-\frac{\sum_{\mathrm{i}=1}^{\mathrm{j}-1} \mathrm{c}^{(\mathrm{i})} \mathrm{t}_{\mathrm{f}}^{(\mathrm{i})}}{\mathrm{h}}\right]^{2}\right\} \text { otherwise. }
\end{aligned}
$$

Eq. (6) clearly indicates that if $h>\sum_{i=1}^{j} C^{(i)} t_{f}^{(i)}$ the actual volume fraction of the jth layer of the multilayer coating, contributing to the composite hardness, can be computed from the difference between the volume fraction of such a layer and the preceding one. Both fractions are calculated on the basis of Eq. (1), by taking into account the number of layers involved in the indentation process. This procedure is equivalent to compute the volume fraction of the jth layer by means of Eq. (1) and subtract the fractions of the previous layers. Thus, once the volume fraction of each layer has been computed, the volume fraction corresponding to the substrate material can be obtained:

$a_{\mathrm{f}}{ }^{(S)}=1-\sum_{i=1}^{N} a_{f}{ }^{(i)}$.

The composite hardness of the multilayer coating would then be given by:

$\mathrm{H}_{\mathrm{c}}=\sum_{\mathrm{i}=1}^{\mathrm{N}} \mathrm{a}_{\mathrm{f}}^{(\mathrm{i})} \mathrm{H}_{\mathrm{f}}^{(\mathrm{i})}+\mathrm{a}_{\mathrm{f}}^{(\mathrm{S})} \mathrm{H}_{\mathrm{s}}$

If required, an indentation size effect (ISE) for the different layers and substrate can be considered, by assuming that [45]:

$\mathrm{H}_{\mathrm{f}}^{\left({ }^{(i)}\right.}=\mathrm{H}_{\mathrm{fo}}{ }^{(\mathrm{i})}+\frac{\mathrm{B}^{(\mathrm{i})}}{\mathrm{h}}$ and $\mathrm{H}_{\mathrm{s}}=\mathrm{H}_{\mathrm{s} 0}+\frac{\mathrm{B}_{\mathrm{s}}}{\mathrm{h}}$

Therefore, Eqs. (4) through (9) encompass the computational procedure that should be followed in order to determine the change in the composite hardness with penetration depth for a multilayer coating, according to the model advanced by Iost et al. [45]. Also, by means of non-linear least square analysis, it allows the computation of the intrinsic hardness of each layer, as well as that of the substrate.

In the above equations $a_{f}^{(i)}$ and $a_{f}^{(j)}$ represent the volume fraction of any layer in the coating, which contributes to the composite hardness, $a_{f}^{(S)}$ the volume fraction of substrate, $C^{(i)}$ the corresponding value of the geometrical constant for the ith layer under consideration, which depends on its indentation behavior, $\mathrm{t}_{\mathrm{f}}^{\mathrm{i})}$ its thickness and $\mathrm{H}_{\mathrm{f}}^{(\mathrm{i})}$ its hardness. $\mathrm{H}_{\mathrm{fo}}$ and $\mathrm{H}_{\mathrm{s}}$ represent the intrinsic hardness (disregarding any ISE) of the ith layer and substrate, respectively, whereas $B^{(i)}$ and $B_{s}$ the corresponding ISE parameters.
2.1. A modified form of the models advanced by Korsunsky et al. [39-41] and Puchi-Cabrera [42,43]

According to the model originally advanced by Korsunsky et al. [39] $(\mathrm{K})$, based on the work of indentation, the volume fraction of coating that contributes to the composite hardness can be expressed in terms of penetration depth by the following equation:

$$
\mathrm{a}_{\mathrm{f}}=\frac{1}{1+\left(\frac{\mathrm{h}}{\beta_{0} \mathrm{t}_{\mathrm{f}}}\right)^{2}} \text {. }
$$

The above equation was subsequently generalized $[40,41]$ to the following expression:

$\mathrm{a}_{\mathrm{f}}=\frac{1}{1+\left(\frac{\mathrm{h}}{\beta_{\mathrm{k}} \mathrm{t}_{\mathrm{f}}}\right)^{\mathrm{n}_{\mathrm{k}}}}$

in order to allow values for the exponent other than 2 .

On the other hand, as far as the model advanced by Puchi-Cabrera $[42,43](\mathrm{PC})$ is concerned, the volume fraction of coating can also be expressed as:

$\left.a_{f}=\exp -\frac{h}{\beta_{p} t_{f}}\right)^{n_{p}}$.

In Eqs. (10) through (12), $\beta_{\mathrm{k}}, \beta_{\mathrm{p}}, \mathrm{n}_{\mathrm{k}}$ and $\mathrm{n}_{\mathrm{p}}$ represent material parameters characteristic of the coated system. Particularly, the parameter $\beta$ in Eqs. (10) through (12) physically represents the ratio $h / t$ for which the fraction $\left(\mathrm{H}_{\mathrm{C}}-\mathrm{H}_{\mathrm{S}}\right) /\left(\mathrm{H}_{\mathrm{F}}-\mathrm{H}_{\mathrm{S}}\right)$ achieves a given constant value, depending on the model under consideration. In the case of the $\mathrm{K}$ model such a fraction is equal to 0.5 , whereas in the PC model, it is of approximately 0.37 . As can be clearly observed, for both models $0 \leq \mathrm{a}_{\mathrm{f}} \leq 1$, which allows the determination of the composite hardness of a coated system by means of Eq. (3).

The modification and computational implementation of both models, in order to describe the composite hardness of a coated system involving a multilayer coating, based on the ideas developed by lost et al. [45], could be conducted as illustrated below. In the case of the Korsunsky et al. model, for the first layer of the multilayer coating, the volume fraction can be re-defined as:

$$
\begin{array}{ll}
\mathrm{a}_{\mathrm{f}}{ }^{(1)}=1 & \text { if } \mathrm{h}<\mathrm{K}_{\mathrm{f}}{ }^{(1)} \mathrm{t}_{\mathrm{f}}{ }^{(1)} \\
\mathrm{a}_{\mathrm{f}}{ }^{(1)}=\frac{1}{1+\left(\frac{\mathrm{h}-\mathrm{K}_{\mathrm{f}}^{(1)} \mathrm{t}_{\mathrm{f}}^{(1)}}{\beta_{\mathrm{k}}{ }^{(1)} \mathrm{t}_{\mathrm{f}}{ }^{(1)}}\right)^{2}} & \text { otherwise. }
\end{array}
$$

For the jth layer of the coating:

$$
\mathrm{a}_{\mathrm{f}}{ }^{(\mathrm{j})}=1-\sum_{\mathrm{i}=1}^{\mathrm{j}-1} \mathrm{a}_{\mathrm{f}}{ }^{(\mathrm{i})} \quad \text { if } \mathrm{h}<\sum_{\mathrm{i}=1}^{\mathrm{j}} \mathrm{K}_{\mathrm{f}}{ }^{(\mathrm{i})} \mathrm{t}_{\mathrm{f}}{ }^{(\mathrm{i})}
$$

Otherwise:

$$
\begin{aligned}
& \mathrm{a}_{\mathrm{f}}{ }^{(\mathrm{j})}=\frac{1}{1+\left(\frac{\mathrm{h}-\sum_{\mathrm{i}=1}^{\mathrm{j}} \mathrm{K}_{\mathrm{f}}^{(i)} \mathrm{t}_{\mathrm{f}}^{(i)}}{\beta_{\mathrm{k}}{ }^{(j)} \sum_{\mathrm{i}=1}^{\mathrm{j}} \mathrm{t}_{\mathrm{f}}{ }^{(i)}}\right)^{2}}-\frac{1}{1+\left(\frac{\mathrm{h}-\sum_{\mathrm{i}=1}^{\mathrm{j}-1} \mathrm{~K}_{\mathrm{f}}{ }^{(\mathrm{i})} \mathrm{t}_{\mathrm{f}}{ }^{(i)}}{\beta_{\mathrm{k}}{ }^{(j-1)} \sum_{\mathrm{i}=1}^{\mathrm{j}-1} \mathrm{t}_{\mathrm{f}}{ }^{(i)}}\right)^{2}}= \\
& 1+\left(\frac{1}{h-\sum_{i=1}^{j} K_{f}^{(i)} t_{f}^{(i)}}\right)^{2}-\sum_{i=1}^{j-1} a_{f}^{(i)} \sum_{i=1}^{j} t_{f}^{(i)} \text {. }
\end{aligned}
$$


In the case of the model advanced by Puchi-Cabrera [42,43] (PC), for the first layer of the coating the volume fraction would be given by:

$$
\begin{array}{ll}
\mathrm{a}_{\mathrm{f}}{ }^{(1)}=1 & \text { if } \mathrm{h}<\mathrm{K}_{\mathrm{f}}{ }^{(1)} \\
\left.\mathrm{a}_{\mathrm{f}}{ }^{(1)}=\exp \left[-\frac{\mathrm{h}-\mathrm{K}_{\mathrm{f}}{ }^{(1)} \mathrm{t}_{\mathrm{f}}{ }^{(1)}}{\beta_{\mathrm{p}}{ }^{(1)} \mathrm{t}_{\mathrm{f}}{ }^{(1)}}\right)^{2}\right] & \text { otherwise }
\end{array}
$$

and for the jth layer of the coating:

$$
\mathrm{a}_{\mathrm{f}}{ }^{(\mathrm{j})}=1-\sum_{\mathrm{i}=1}^{\mathrm{j}-1} \mathrm{a}_{\mathrm{f}}{ }^{(\mathrm{i})} \quad \text { if } \mathrm{h}<\sum_{\mathrm{i}=1}^{\mathrm{j}} \mathrm{K}_{\mathrm{f}}{ }^{(\mathrm{i})} \mathrm{t}_{\mathrm{f}}{ }^{(\mathrm{i})}
$$

Otherwise:

$$
\begin{aligned}
a_{f}^{(j)} & =\exp \left[-\left(\frac{h-\sum_{i=1}^{j} K_{f}^{(i)} t_{f}^{(i)}}{\beta_{p}{ }^{(j)} \sum_{i=1}^{j} t_{f}^{(i)}}\right)^{2}\right]-\exp \left[-\left(\frac{h-\sum_{i=1}^{j-1} K_{f}^{(i)} t_{f}{ }^{(i)}}{\beta_{p}{ }^{(j-1)} \sum_{i=1}^{j-1} t_{f}{ }^{(i)}}\right)^{2}\right]= \\
& =\exp \left[-\left(\frac{h-\sum_{i=1}^{j} K_{f}^{(i)} t_{f}^{(i)}}{\beta_{p}{ }^{(j)} \sum_{i=1}^{j} t_{f}{ }^{(i)}}\right)\right]-\sum_{i=1}^{j-1} a_{f}{ }^{(i)} .
\end{aligned}
$$

In Eqs. (13) through (16), $\mathrm{K}_{\mathrm{f}}^{(\mathrm{i})}$ represents the fraction of the $\mathrm{i}^{\text {th }}$ layer thickness above which either the layers below or substrate will start to contribute to the composite hardness. For both models, the exponents involved in the definition of the different volume fractions have been set to 2, as in the original model advanced by Korsunsky et al. [39]. Finally, the computation of the volume fraction of the substrate, as well as the composite hardness of the coated system can be accomplished by means of Eqs. (7) and (8), allowing also for the possibility of introducing an ISE by means of Eq. (9).

The illustration of the applicability of these modified versions of the models advanced by Korsunsky et al. [39-41] and Puchi-Cabrera [42,43] will be presented in the next section, regarding the analysis of the indentation behavior of a 2024-T6 aluminum alloy coated with a DLC film, employing a NiP plating as intermediate layer. The results provided by these two models will also be compared with that obtained from the modified JH model.

\section{Experimental materials and techniques}

The modified models presented in the previous section were validated employing the nanoindentation data obtained from a coated system consisting of a 2024-T6 aluminum alloy, which was plated with a NiP coating, as intermediate layer and subsequently coated with a hydrogenated a-C:H diamond-like carbon (DLC) film, commercially known as Dymon-iC ${ }^{\mathrm{TM}}$. Physical vapor deposition (PVD) was carried out by Teer Coatings, U.K., by means of closed field unbalanced magnetron sputtering ion platting (CFUBMSIP), coupled with plasma assisted chemical vapor deposition (PACVD). Details of the deposition techniques and characterization of the coated system are given elsewhere $[48,49]$.

The hardness versus penetration depth data was determined by means of nanoindentation tests using a MTS XP Nano Indenter under a continuous stiffness measurement mode and equipped with a Berkovich indenter. Prior to indentation tests, the calibration of the indenter tip was carried out employing a fused silica sample. 25 indentations were conducted on three different samples of the coated system and the hardness versus indentation depth was recorded continuously up to approximately $7000 \mathrm{~nm}$, at a constant indentation rate of $0.05 \mathrm{~s}^{-1}$. The results were analyzed by means of the Oliver and Pharr method [50]. Thus, Fig. 1a and b illustrate typical
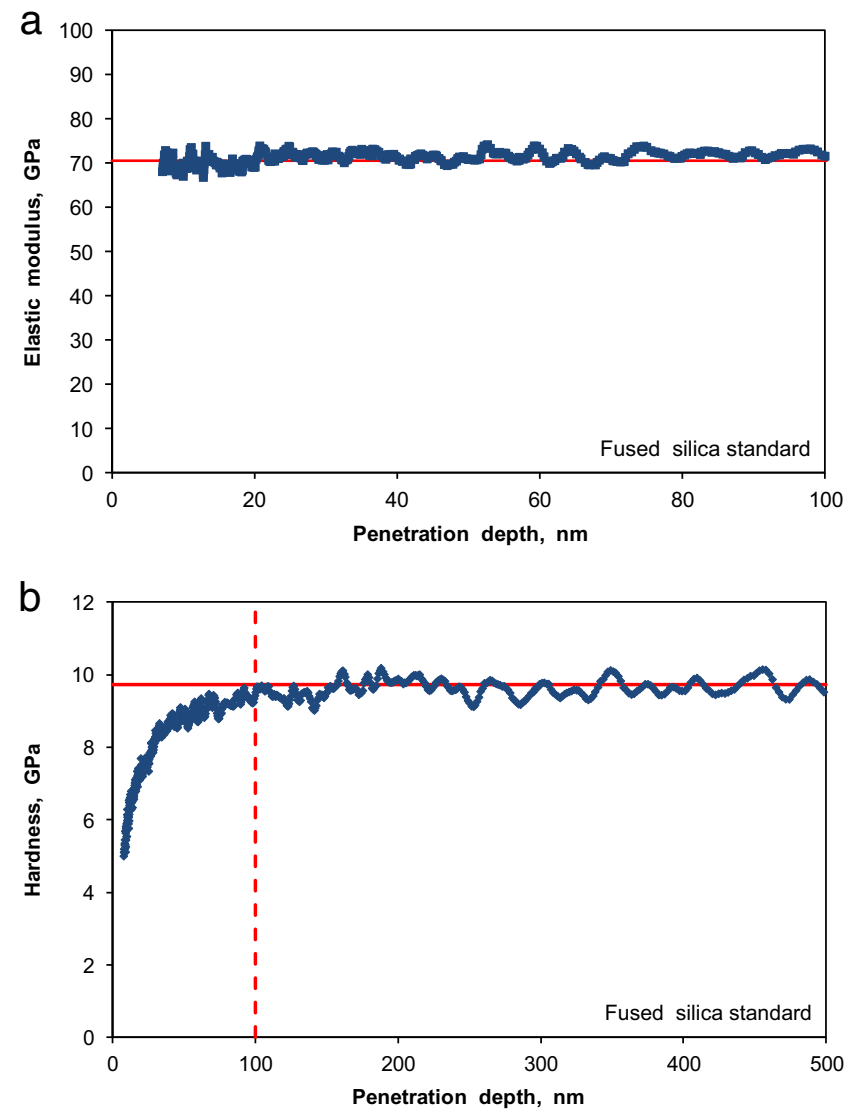

Fig. 1. Calibration curves for the Berkovich indenter employed in the present investigation, by means of fused silica standard. (a) Change in the elastic modulus with indentation depth. A constant value is obtained from approximately $7 \mathrm{~nm}$ penetration depth. (b) Change in hardness with indentation depth. A constant value is achieved from approximately $100 \mathrm{~nm}$ penetration depth.

curves showing the change both in elastic modulus and hardness for the fused silica standard. It can be clearly observed that the elastic modulus remains constant at penetration depths greater than approximately $7 \mathrm{~nm}$, whereas the hardness achieves a constant value above approximately $100 \mathrm{~nm}$. Therefore, in order to test the different hardness models studied in the present investigation, the hardness data determined at indentation depths less than $100 \mathrm{~nm}$ were disregarded.

Prior to the deposition of the DLC coating, a $\mathrm{CrC}$ intermediate layer was deposited onto the NiP plating. Therefore, in principle, the coated system encompasses a DLC coating and a $\mathrm{CrC}$ film, which together have a thickness of approximately $2.2 \mu \mathrm{m}$, and an electroless NiP plating with a thickness of about $52 \mu \mathrm{m}$, all of which are deposited onto the aluminum alloy substrate. However, the detailed analysis conducted by Staia et al. [49] indicates that during PVD deposition, a diffusive reaction between the DLC, $\mathrm{CrC}$ and $\mathrm{NiP}$ took place, which occurred over a distance of approximately $4 \mu \mathrm{m}$ into the $\mathrm{NiP}$ from the $\mathrm{CrC}-\mathrm{NiP}$ interface, giving rise to the presence of another layer of CNiPCr. Fig. 2 illustrates a scanning electron microscopy (SEM) cross section view of the coated system after fracture, showing the approximate location of the different layers, which encompass the multilayer coating.

Therefore, as far as the validation of the proposed models is concerned, the multilayer coating will be considered as a first layer of DLC with a thickness of $900 \mathrm{~nm}$, a second layer of $\mathrm{CrC}$ with a thickness of $1200 \mathrm{~nm}$ and a diffusive layer of CNiPCr with a thickness of $4000 \mathrm{~nm}$. The electroless NiP plating, with a thickness of $48 \mu \mathrm{m}$, is considered as the substrate for all practical purposes. 


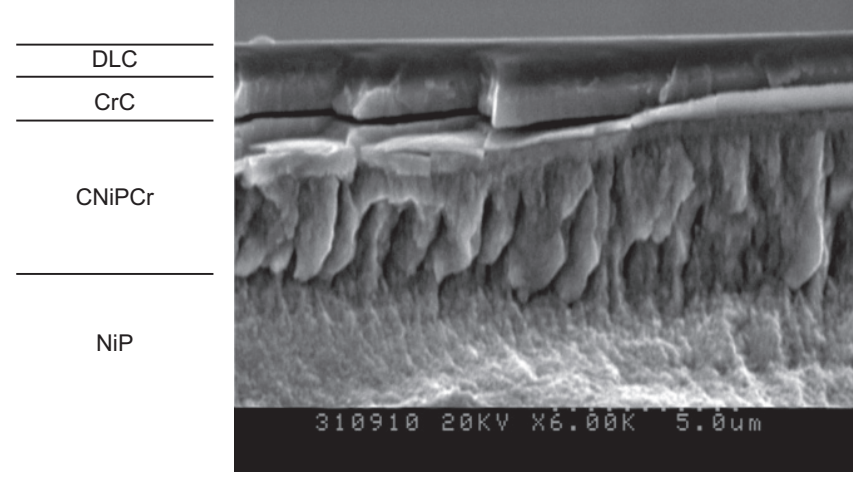

Fig. 2. SEM cross section view of the coated system under investigation after fracture, showing the DLC, CrC and CNiPCr layers, as well as the NiP substrate.

\section{Experimental results}

Fig. 3 illustrates the change in the composite hardness as a function of penetration depth as determined from the nanoindentation tests. The experimental data encompasses approximately 20 thousand points and shows the scatter band usually observed for this kind of test. The maximum hardness value, somewhat above $14 \mathrm{GPa}$, is obtained at penetration depths of approximately $400 \mathrm{~nm}$, which represents somewhat less than $50 \%$ of the DLC coating thickness. Therefore, it is expected that the increase in hardness is associated with the presence of the $\mathrm{CrC}$ layer located below the DLC coating. Furthermore, the subsequent decrease in hardness observed for penetration depths greater than $400 \mathrm{~nm}$ indicates that the $\mathrm{CrC}$ layer should exhibit the highest intrinsic hardness of the different layers, which compose the multilayer coating, as it should be confirmed from the modeling results.

The preliminary description of the experimental data by means of the modified $\mathrm{JH}$ model indicates, according to the different values determined for the constant $\mathrm{C}$, that under indentation loading the DLC layer tends to fracture, whereas the $\mathrm{CrC}$ and $\mathrm{CNiPCr}$ layers tend to deform plastically. Therefore, by setting $C^{(\mathrm{DLC})}=0.0915$ and $\mathrm{C}^{(\mathrm{CrC})}=\mathrm{C}^{(\mathrm{CNiPCr})}=$ 0.1746 , a non-linear least squares analysis can be conducted in order to determine the intrinsic hardness of the different layers, as well as that of the NiP substrate. Fig. 3 illustrates the final description of the experimental hardness data by means of this model, after imposing the above conditions. Table 1 summarizes the values of the different parameters involved in the model. Also, the Table includes the value of the mean square error (MSE), defined as: $\Omega /\left(\mathrm{N}-\mathrm{N}_{\mathrm{p}}\right)$, where $\Omega$ represents the objective function or sum of squares, $\mathrm{N}$ the number of experimental data points and $\mathrm{N}_{\mathrm{p}}$ the number of parameters employed in the fit. In this

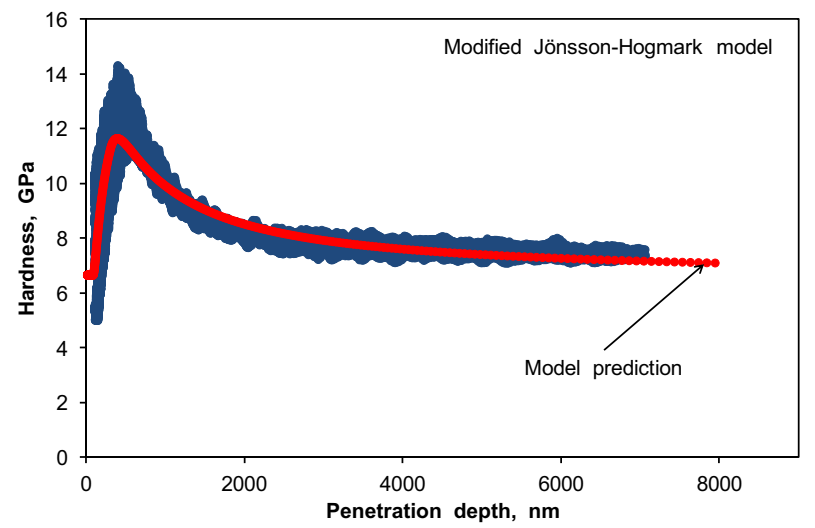

Fig. 3. Change in the experimental values of the composite hardness as a function of penetration depth for the coated system under investigation. The description of the experimental data has been conducted with the modified JH model.
Table 1

Parameters involved in the modified Jönsson-Hogmark model.

\begin{tabular}{lc}
$\mathrm{C}^{(\mathrm{DLC})}$ & 0.0915 \\
$\mathrm{H}_{\mathrm{DLC}}, \mathrm{GPa}$ & 6.7 \\
$\mathrm{C}^{(\mathrm{CrC})}$ & 0.1746 \\
$\mathrm{H}_{\mathrm{CrC}}, \mathrm{GPa}$ & 15.4 \\
$\mathrm{C}^{(\mathrm{CNiPCr})}$ & 0.1746 \\
$\mathrm{H}_{\mathrm{CNiPCr}}, \mathrm{GPa}$ & 7.0 \\
$\mathrm{H}_{\mathrm{NiP}}, \mathrm{GPa}$ & 6.6 \\
$\left(\frac{\Omega}{\mathrm{N}-\mathrm{N}_{\mathrm{p}}}\right), \mathrm{GPa}^{2}$ & 1.4 \\
\hline
\end{tabular}

way, a rational comparison among the different hardness models could be made.

As can be observed in Fig. 3, taking into consideration that only four parameters have been fitted with the least-squares procedure, the modified $\mathrm{JH}$ model is able to provide a satisfactory description of the change in the composite hardness of the coated system as a function of penetration depth. Accordingly, the model predicts that from the surface of the DLC layer up to a penetration depth of approximately $82 \mathrm{~nm}$ the composite hardness will remain constant and its value will be determined by the intrinsic hardness of the DLC layer.

As the penetration depth increases the $\mathrm{CrC}$ layer starts to contribute to the composite hardness and up to a penetration depth of approximately $300 \mathrm{~nm}$ the composite hardness will be determined by these two layers. For penetration depth values greater than $300 \mathrm{~nm}$ the $\mathrm{CNiPCr}$ layer starts to contribute to the composite hardness. However, despite the fact that its intrinsic hardness is less than that of the $\mathrm{CrC}$ layer, the composite hardness continues to increase up to approximately $410 \mathrm{~nm}$. Thus, from this penetration depth up to approximately $1000 \mathrm{~nm}$, the composite hardness is solely determined by the first three layers and beyond $1000 \mathrm{~nm}$, the substrate will start to contribute to its value, giving rise to a further decrease, as shown by the predicted curve in Fig. 3.

The contribution of each layer to the evolution of the composite hardness with penetration depth, according to this model, can be clearly observed in Fig. 4. This Figure illustrates the change in the volume fraction of each layer contributing to the composite hardness as a function of penetration depth, a convenient form of representation that was proposed by Iost et al. [45]. Thus, the different penetration range intervals over which each particular layer of the multilayer coating dominates the contribution to the composite hardness, can be easily determined. However, these features are significantly dependent on the model employed for the description of the composite hardness.

The results concerning the use of the modified form of the Korsunsky et al. model (K) are shown in Fig. 5 and the value of the different

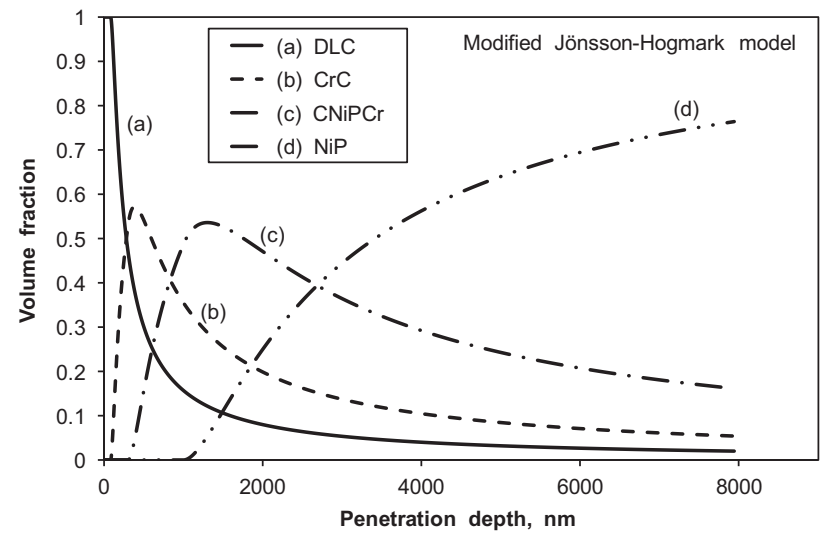

Fig. 4. Change in the volume fraction of each coating contributing to the composite hardness, according to the $\mathrm{JH}$ model, as a function of penetration depth. 


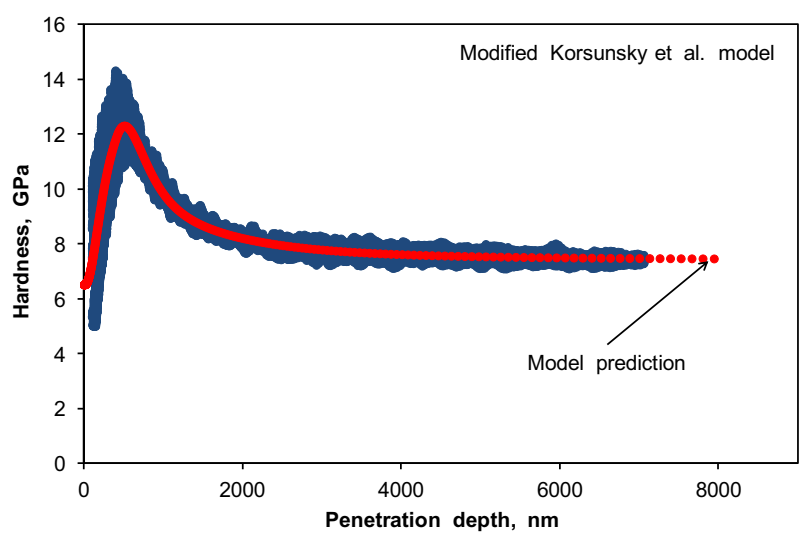

Fig. 5. Change in the experimental values of the composite hardness as a function of penetration depth for the coated system under investigation. The description of the experimental data has been conducted with the modified $\mathrm{K}$ model.

Table 2

Parameters involved in the modified Korsunsky et al. model.

\begin{tabular}{lc}
\hline $\mathrm{H}_{\mathrm{DLC}}, \mathrm{GPa}$ & 6.5 \\
$\beta_{\mathrm{DLC}}$ & 0.292 \\
$\mathrm{~K}_{\mathrm{f}}^{(\mathrm{DLC})}$ & 0.01 \\
$\mathrm{H}_{\mathrm{CrC}}, \mathrm{GPa}$ & 14.2 \\
$\beta_{\mathrm{CrC}}$ & 0.21 \\
$\mathrm{~K}_{\mathrm{f}}^{(\mathrm{CrC})}$ & 0.32 \\
$\mathrm{H}_{\mathrm{CNiPCr}}, \mathrm{GPa}$ & 8 \\
$\beta_{\mathrm{CNiPCr}}$ & 0.251 \\
$\mathrm{~K}_{\mathrm{f}}^{(\mathrm{CNiPC})}$ & 0.19 \\
$\mathrm{H}_{\mathrm{NiP}}, \mathrm{GPa}$ & 7.4 \\
$\left(\frac{\Omega}{\mathrm{N}-\mathrm{N}_{\mathrm{p}}}\right), \mathrm{GPa}^{2}$ & 1.19 \\
\hline
\end{tabular}

parameters involved are presented in Table 2. As can be observed in this Figure, the modified $\mathrm{K}$ model provides an excellent description of the experimental composite hardness data, which of course is achieved at the expense of a significant increase in the number of parameters employed. Contrary to the modified JH model, the modified $\mathrm{K}$ model predicts the fracture of the DLC layer at an earlier stage, as well as the initiation of the contribution of the $\mathrm{CrC}$ layer to the composite hardness. These features can be clearly observed in Fig. 6, which illustrates the change in layer volume fraction as a function of penetration depth for this model.

In order to compute the intrinsic hardness of the different layers by means of this model, the corresponding parameters $K_{f}^{(i)}$, which represent the fraction of the coating thickness from which the layers below

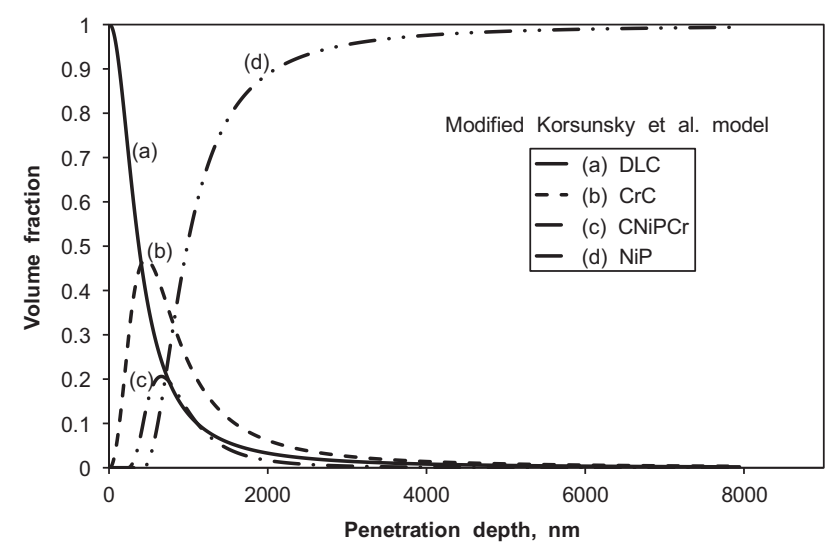

Fig. 6. Change in the volume fraction of each coating contributing to the composite hardness, according to the $\mathrm{K}$ model, as a function of penetration depth.

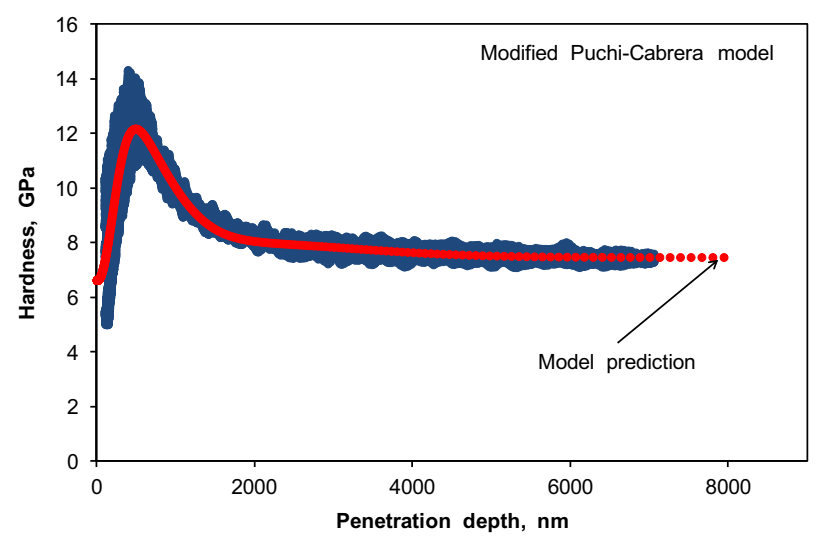

Fig. 7. Change in the experimental values of the composite hardness as a function of penetration depth for the coated system under investigation. The description of the experimental data has been conducted with the modified PC model.

starts to contribute to the composite hardness, were allowed a range interval between 0.01 and 1 . Thus, whereas for the JH model such fractions have fixed values, depending on the behavior of the material under indentation loading, for the modified $\mathrm{K}$ model these fractions can take a wide range of values, representing three parameters to be fitted. An interesting observation concerning Table 2 is that the different $\beta_{\mathrm{k}}$ values remain in a short range interval, between approximately $0.2-$ 0.3. Therefore, in principle, it would be possible to assume a mean constant value of such a parameter for the different layers, with the consequent reduction in the number of constants to be fitted.

Regarding the modified model advanced by Puchi-Cabrera (PC), Fig. 7 illustrates the corresponding description of the experimental composite hardness values as a function of penetration depth and Table 3 summarizes the magnitude of the different parameters involved in the fit. This model also provides a satisfactory prediction of the changes in the composite hardness with the increase in the indenter displacement, similar to the two previous models. However, two important differences should be pointed out after comparing the results provided by this model with those provided by the modified K model.

In the first place, the range interval for the $\beta_{p}$ values spans from approximately 0.31 to 0.43 . Secondly, the MSE is slightly higher than in the previous case. Therefore, it would be also interesting to explore the possibilities of assigning a mean constant value to $\beta_{\mathrm{p}}$, in terms of the change in the mean square error. Such an analysis for both the modified $\mathrm{K}$ and PC models will be conducted in the next section.

An interesting feature of the modified $\mathrm{K}$ and $\mathrm{PC}$ models is the prediction of a hardness value for the electroless NiP "substrate" in the range of approximately $7.5 \mathrm{GPa}$, which agrees very well with the value reported by Staia et al. [49] of $7.7 \pm 0.5 \mathrm{GPa}$. The latter value was obtained experimentally from nanoindentation tests carried out on one of the PVD deposited samples, but on its reverse side, where the DLC coating was not deposited.

Table 3

Parameters involved in the modified Puchi-Cabrera model.

\begin{tabular}{lc}
\hline $\mathrm{H}_{\mathrm{DLC}}, \mathrm{GPa}$ & 6.6 \\
$\beta_{\mathrm{DLC}}$ & 0.313 \\
$\mathrm{~K}_{\mathrm{f}}^{(\mathrm{DLC})}$ & 0.01 \\
$\mathrm{H}_{\mathrm{CrC}}, \mathrm{GPa}$ & 13.7 \\
$\beta_{\mathrm{CrC}}$ & 0.428 \\
$\mathrm{~K}_{\mathrm{f}}^{(\mathrm{CrC})}$ & 0.04 \\
$\mathrm{H}_{\mathrm{CNiPCr}}, \mathrm{GPa}$ & 8 \\
$\beta_{\mathrm{CNiPCr}}$ & 0.359 \\
$\mathrm{~K}_{\mathrm{f}}^{(\mathrm{CNiPCr})}$ & 0.41 \\
$\mathrm{H}_{\mathrm{NiP}}, \mathrm{GPa}$ & 7.5 \\
$\left(\frac{\Omega}{\mathrm{N}-\mathrm{N}_{\mathrm{p}}}\right), \mathrm{GPa}^{2}$ & 1.20 \\
\hline
\end{tabular}




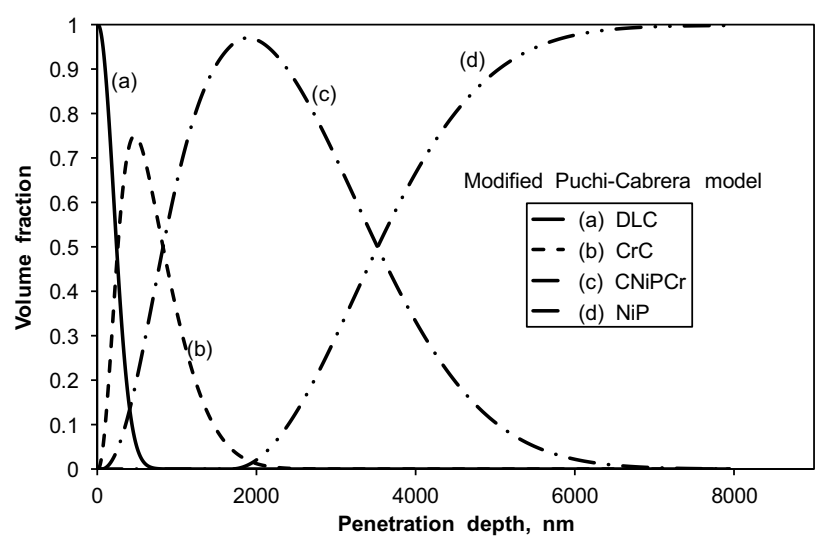

Fig. 8. Change in the volume fraction of each coating contributing to the composite hardness, according to the PC model, as a function of penetration depth.

The change in the volume fraction of each layer, which contributes to the composite hardness, according to the modified PC model, is shown in Fig. 8. As can be observed, according to this model the DLC film exerts the major influence in the value of the composite hardness up to indentation depths in the range of $250 \mathrm{~nm}$. As the indentation depth continues to increase up to about $830 \mathrm{~nm}$, the $\mathrm{CrC}$ layer becomes the determining coating regarding the indentation response of the coated system. This explains the achievement of the maximum composite hardness at approximately $500 \mathrm{~nm}$ and its subsequent decrease due to the increasing influence of the $\mathrm{CNiPCr}$ layer. The latter will determine the change in the composite hardness up to penetration depths of about $3500 \mathrm{~nm}$, when the electroless NiP "substrate" will become the prevailing layer.

Thus, for each of the composite hardness models that have been presented, it is possible to envisage the way in which each of the layers of the multilayer coating contributes to the determination of the hardness response of the coated system, depending on its location, the behavior that it exhibits during indentation loading and the relative displacement of the indenter. Clearly, the quality of the theoretical description of the model depends on the number of parameters employed in the fit, which in turn determines the MSE associated to the model.

\section{Discussion}

In a recent paper, Iost et al. [51] analyzed the robustness of different models employed for the description of the composited hardness of coated systems, which involve the deposition of monolayer coatings, and the determination of the intrinsic hardness of both coating and substrate. This analysis encompassed the original models proposed by Jönsson and Hogmark [36], Korsunsky et al. [39-41] and Puchi-Cabrera [42,43]. The results of this analysis indicated that the $\mathrm{JH}$ model is the most robust of all due to the small number of parameters, which are employed in the fit of the experimental data. The results obtained in the present work effectively indicate that the modified $\mathrm{JH}$ model is able to provide a good description of the change in the experimental composite hardness versus penetration depth data, as well as estimate correctly the intrinsic hardness of the substrate. Also, the preliminary evaluation of the composite hardness data by means of this model allows an indication of the way in which each layer is expected to behave under indentation loading: fracture in the case of the DLC film and plastic deformation in the case of the $\mathrm{CrC}$ and $\mathrm{CNiPCr}$ layers.

On the other hand, the modified $\mathrm{K}$ and PC models are able to describe more precisely the change in the composite hardness with indentation depth than the $\mathrm{JH}$ model, but at the expense of a significant increase in the number of parameters involved in the models. Both approaches also provide a reasonable estimate of the substrate hardness, indicated by the independent evaluation of the hardness of the latter.
Regarding the intrinsic hardness value of the different layers involved in the coating, it is interesting to observe that the three models predict a hardness in the range of 6-7 GPa for the DLC film, which is much lower than that reported both by Jarratt et al. [48] and the ISO14577-4 standard (DLC film of approximately $2.5 \mu \mathrm{m}$ in thickness) [52], of approximately $18 \mathrm{GPa}$. However, since the hardness data considered in the analysis correspond to penetration depths greater than $100 \mathrm{~nm}$, as indicated in Fig. 1b, it is unlikely that such a low hardness value found in the present work for the DLC coating would be due to the way in which the plastic zone develops during indentation employing a sharp indenter. It is a well known fact that under these conditions, the plastic zone develops from an inhomogeneous zone caused by a defective tip indenter, until it reaches a fully developed zone, which expands radially. During the development of the plastic zone the contact pressure increases and the hardness of the coating is then determined when the plastic zone is fully developed and a plateau is achieved on the hardness versus penetration depth curve.

Fig. 9 illustrates the experimental hardness versus penetration depth curves in the interval of 100 to $500 \mathrm{~nm}$. After $100 \mathrm{~nm}$ of indentation depth, it is expected that the plastic zone under the indenter is fully developed, which would indicate a hardness for the DLC film in the range of 5-10 GPa, in agreement with the predictions of the models. As penetration depth increases further, the hardness also increases as a consequence of the harder $\mathrm{CrC}$ interlayer and tends to achieve a maximum value of approximately $14 \mathrm{GPa}$ at about $500 \mathrm{~nm}$. The subsequent decrease in the composite hardness occurs due to the influences of the $\mathrm{CNiPCr}$ layer and the NiP substrate.

The relatively low hardness value that has been found for the DLC film in the present work could be due to different reasons. In the first place, it is well known that the hardness of DLC films deposited by PVD processes depends significantly on the deposition conditions. The work conducted by Michler et al. [53] indicates that amorphous hydrogenated carbon films can exhibit hardness values in the range of approximately 5-23 GPa, depending on the ratio $\mathrm{J} / \mathrm{p}^{0.6}$ and $\mathrm{CH}_{4}$ flow. Here, $\mathrm{J}$ represents the current density and p, the pressure. Also, Li et al. [54] found that hydrogenated amorphous carbon (a-C:H) films can have hardness values in the range of 9-14 GPa, when the bias voltage increased from 100 to $500 \mathrm{~V}$. Yamamoto and Matsukado [55] also determined that hydrogenated DLC coatings, deposited by means of unbalanced magnetron sputtering, could exhibit a hardness value in the range of approximately 5-22 GPa, when the bias voltage applied during deposition increased from 0 to $100 \mathrm{~V}$.

However, not only deposition conditions could have a significant influence on this mechanical property, but also the intrinsic defects present in the film could play an important role. It is well known that porosity could give rise to a significant decrease in the mechanical properties of different materials. In this sense, Luo et al. [56] were able to describe the change in hardness of 3Y-TZP ceramics as a function of their

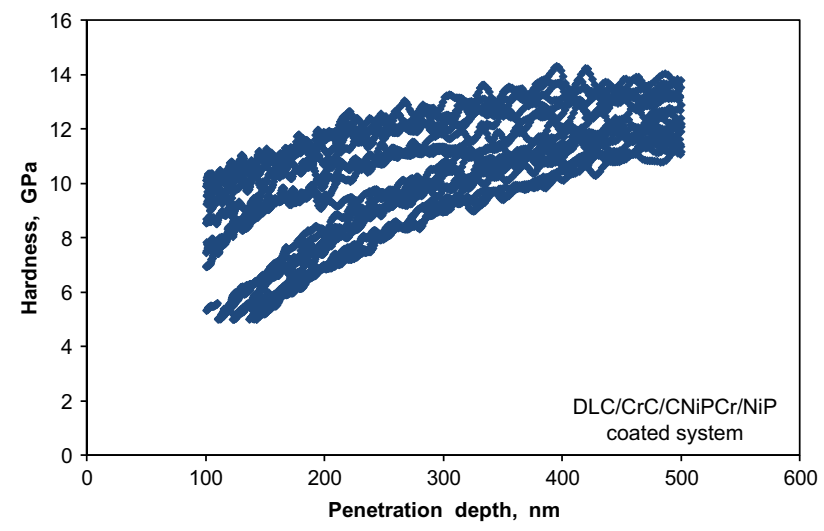

Fig. 9. Experimental hardness versus penetration depth curves represented just in the interval of 100 to $500 \mathrm{~nm}$, illustrating the low hardness value of the DLC film. 
porosity content, $\mathrm{P}$, by means of a simple parametric relationship of the form:

$\mathrm{H}=\mathrm{H}_{0} \exp (-\alpha \mathrm{P})$.

In the above equation, $\mathrm{H}_{0}$ represents the hardness of the fully dense material and $\alpha$ a constant, whose value was found to be 5.02. Also, Adachi et al. [57] described the effect of porosity on the hardness of polycrystalline $\mathrm{ZrN}$ ceramics employing the above equation and found that a value of $\alpha=5.93$ was more appropriate. In the present case, if it is considered that the DLC film has a hardness $\mathrm{H}_{0}=14 \mathrm{GPa}$, which is the value that would had been obtained according to the ISO145774 standard, Eq. (17) would predict a porosity for this material in the range of approximately $12-14 \%$, which would also explain the low hardness value observed.

Besides its low hardness value, the DLC film analyzed in the present investigation also showed the trend of undergoing cracking during indentation, which was observed on the indentation curves as a sudden decrease in hardness with penetration depth, as shown in Fig. 10. Here it is clearly seen that after approximately $14 \mathrm{~nm}$ a sudden and continuous decrease in the composite hardness occurs up to a penetration depth of about $55 \mathrm{~nm}$, after which the hardness increases again. Such a behavior indicates that during indentation loading, nucleation and propagation of cracks occur due to the brittle nature of the film. The latter also justifies that constant $\mathrm{C}^{(\mathrm{DLC})}=0.0915$ in the $\mathrm{JH}$ model and explains the low values of constant $\mathrm{K}_{\mathrm{f}}^{(\mathrm{DLC})}$ that were determined in both the $\mathrm{K}$ and PC models.

As far as the hardness of the $\mathrm{CrC}$ film predicted by the three models analyzed in the present work is concerned, as shown in Table 1 through 3, its value varies between approximately 14-15 GPa. This magnitude is well in the range of the experimental hardness values for different $\mathrm{CrC}$ films of approximately 10.2-18.9 GPa, reported by $\mathrm{Li}$ et al. [58] and very close to the value of $15 \mathrm{GPa}$ found by Hirota and co-workers [59] for $\mathrm{Cr}_{23} \mathrm{C}_{6}$ ceramics sintered at $1150{ }^{\circ} \mathrm{C}$. Regarding the behavior of this material under indentation, better fitting results of the entire hardness versus penetration depth curve by means of the $\mathrm{JH}$ model were obtained by assuming that this film undergoes plastic deformation and therefore, $\mathrm{C}^{(\mathrm{CrC})}=0.1746$. This assumption is also corroborated by the other two models and particularly by the $\mathrm{K}$ model, for which the parameter $\mathrm{K}_{\mathrm{f}}^{(\mathrm{CrC})}=0.32$.

In relation to the $\mathrm{CNiPCr}$ layer, given its diffusive nature and location close to the NiP substrate, both its hardness and mechanical behavior under indentation loading are expected to be very similar to the latter. This is effectively predicted by the three models under consideration, as shown in Tables 1 through 3.

Finally, Fig. 11 illustrates a comparison of the predicted hardness versus penetration depth curves obtained with the three models analyzed in

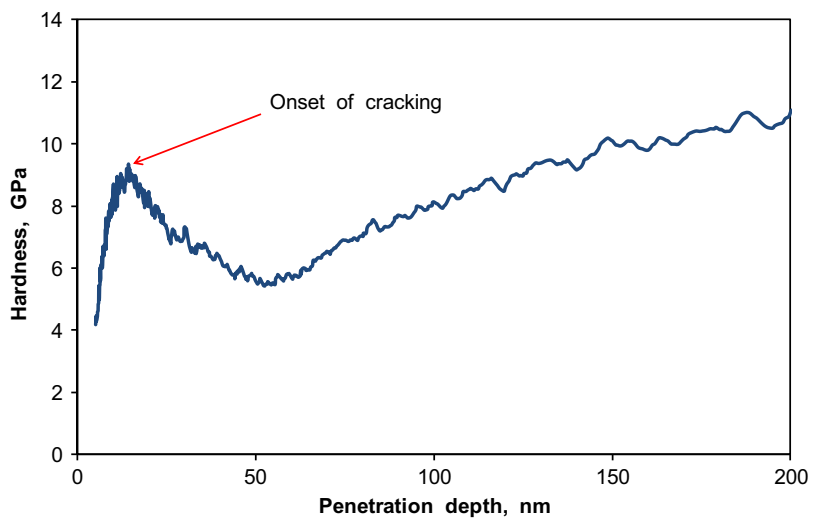

Fig. 10. Typical hardness versus penetration depth curve represented between 5 and $200 \mathrm{~nm}$, illustrating the occurrence of cracking of the DLC film, which shows its brittle behavior under indentation loading.

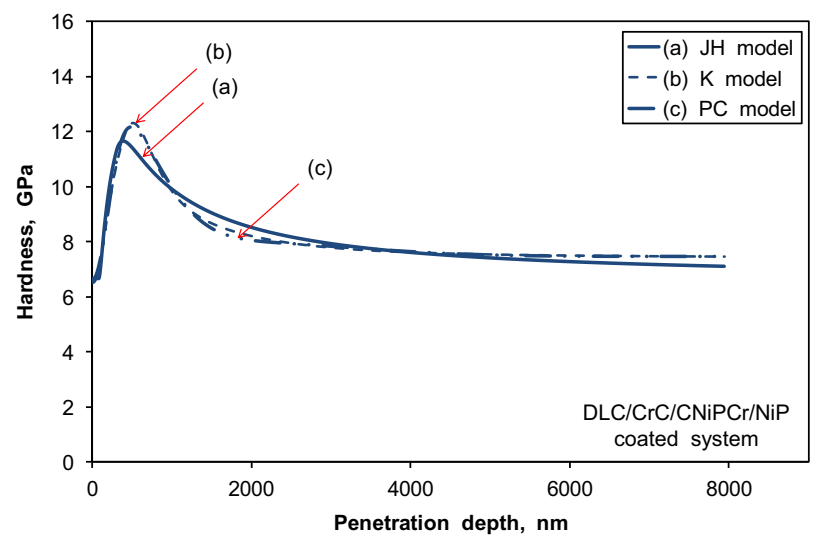

Fig. 11. Comparison of the predicted hardness versus penetration depth curves according to the modified forms of the models advanced by Jönsson-Hogmark $(\mathrm{JH})$, Korsunsky et al. (K) and Puchi-Cabrera (PC).

the present work. As expected, it is observed that both the K and PC models predict a similar description of the experimental data, which renders a decrease in the MSE at the expense of an increase in the number of parameters involved in the fit.

A further improvement of the modified form of the K and PC models would be a rational reduction in the number of parameters involved. For example, taking into consideration that for the modified $\mathrm{K}$ model the $\beta_{\mathrm{k}}$ values ranged between approximately 0.2 and 0.3 , whereas for the PC model the $\beta_{p}$ parameters varied between $0.31-0.43$, an attempt could be made in order to employ a constant value of such parameters in both models, with the consequent reduction of three parameters in the fitting procedure, as well as increasing the models robustness. The unique value of the $\beta_{\mathrm{k}}$ and $\beta_{\mathrm{p}}$ parameter in each model, respectively, can be readily determined as the one which provides the best fit of the entire hardness versus indentation depth curve for each model.

Thus, Fig. 12 illustrates the results provided by the modified $\mathrm{K}$ model, assuming that all the $\beta_{\mathrm{k}}$ values have a constant magnitude of 0.27 . As can be observed from the above Figure, the description of the composite hardness is still very satisfactory and the values of the intrinsic hardness of the different layers do not exhibit significant changes. Also, the MSE increases just to $1.20 \mathrm{MPa}^{2}$, which is still less than that associated with the JH model. In a similar manner, Fig. 13 illustrates the description provided by the modified PC model assuming that $\beta_{\mathrm{p}}=$ 0.36. As with the previous model, the description of the composite hardness is quite satisfactory and the MSE also increases to approximately $1.22 \mathrm{GPa}^{2}$ due to the decrease in the number of parameters involved in the fit.

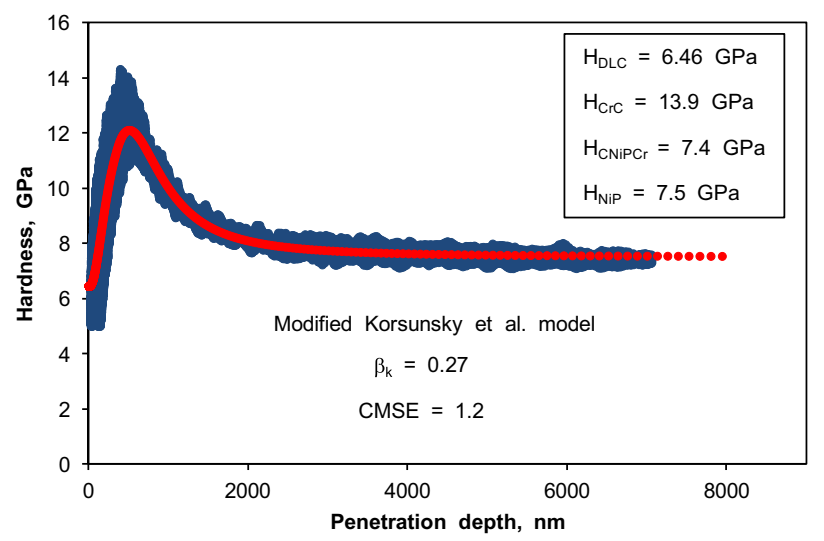

Fig. 12. Description of the experimental data provided by the modified $\mathrm{K}$ model assuming a constant $\beta_{\mathrm{k}}$ value of 0.27 


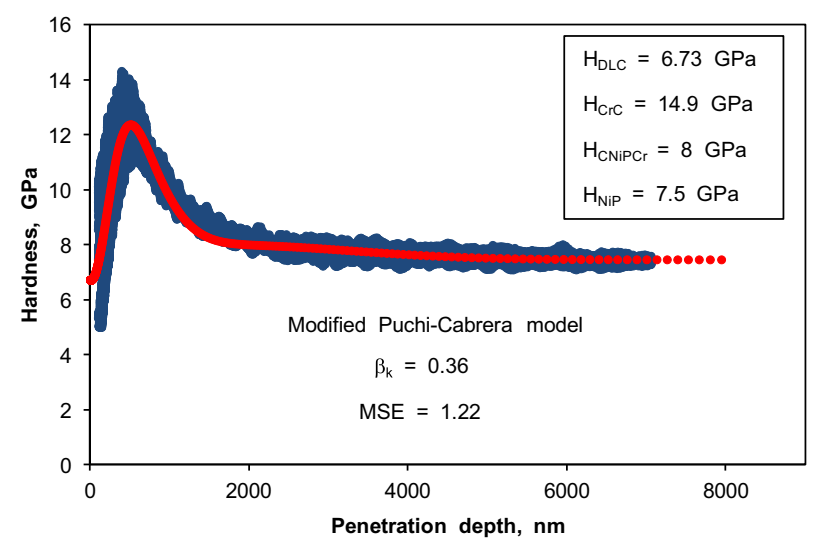

Fig. 13. Description of the experimental data provided by the modified PC model assuming a constant $\beta_{\mathrm{p}}$ value of 0.36 .

The assumption of a constant value for the $\beta_{\mathrm{k}}$ and $\beta_{\mathrm{p}}$ parameters in both models has the further advantage that both approaches for the description of the composite hardness are expressed in terms of parameters with a clear physical significance, including the intrinsic hardness of each layer, the hardness of the substrate and the fraction of coating thickness from which each of the layers start to contribute to the composite hardness. The above analysis also indicates that both $\beta_{\mathrm{k}}$ and $\beta_{\mathrm{P}}$ have a relatively minor impact on the quality of the fit provided by the $\mathrm{K}$ and PC models, respectively. On the contrary, the major influence of the different parameters involved in both models appears to relay on the three variables mentioned above: hardness of each film and substrate, as well as the layer thickness fraction, which determines the onset of its contribution to the composite hardness.

In summary, it can be clearly observed that the description of the change in the composite hardness as a function of penetration depth for coated systems, which involve multilayer coatings, could be conducted by means of different models. As the number of parameters involved in the fitting procedure increases, the robustness of the particular model employed decreases, whereas the MSE also decreases. However, the quality of the description of the experimental data is expected to be significantly better. These features are clearly observed when the results of the modified JH model are compared with those of the modified forms of the K and PC models.

Therefore, the advantages of the different models could be better exploited by making use of them in a combined form. Firstly, a preliminary evaluation of the intrinsic hardness of the different layers, as well as their behavior under indentation loading can be obtained by means of the JH model. Subsequently, this information can be further employed in order to carry out a more precise description of the change in the composite hardness with indentation depth by means of any of the other two models, which require the fit of a larger number of parameters.

\section{Conclusions}

A rational modification of the models earlier advanced by Korsunsky et al. [39-41] and Puchi-Cabrera [42,43], as well as their computational instrumentation, have been conducted, in order to describe appropriately the change in the composite hardness with penetration depth of a coated system, which involves the deposition of a multilayer coating. The extension of both models to deal with multilayer coatings has been conducted on the basis of the methodology proposed by Iost et al. [45], for extending the Jönsson-Hogmark model [36] for a similar purpose. Such a methodology provides a way of computing the volume fraction of each individual layer in the coating, which contributes to the composite hardness. This scheme seems to be general enough to be applicable to different hardness models other than the JH model. It has been shown that the modified forms of both the K and PC models not only provide a satisfactory description of the experimental composite hardness versus penetration depth data, but also allow the computation of the intrinsic hardness of the different layers involved, as well as the hardness of the substrate. It has also been shown that it is possible to express both modified models in terms of parameters, which have a clear physical significance. However, the precise description of the experimental data by means of these two models is achieved at the expense of a significant increase in the number of parameters employed in the fit, which also gives rise to a reduction in the mean squared error, in comparison with the $\mathrm{JH}$ model. Therefore, the combined use of the $\mathrm{JH}$ model with these approaches would allow a better exploitation of the advantages of the different models in the analysis of the indentation behavior of multilayer coatings.

\section{Acknowledgments}

Professor E. S. Puchi-Cabrera gratefully acknowledges the financial support of the Conseil Régional Nord-Pas de Calais, France, through the International Chair program 2011, as well as the CDCH-UCV through the project PG-08-7775-2009/2. Professor Staia also acknowledges the financial support of the Scientific and Humanistic Development Council of the Universidad Central de Venezuela ( $\mathrm{CDCH}-\mathrm{UCV}$ ) through project AIB-08-8539-2012 and to Arts et Métiers Paris Tech, ENSAM Lille, France.

\section{References}

[1] Yin-Yu. Chang, Shun-Jan Yang, Wu. Weite, Yu.-C.hu. Kuo, Jyh-Wei Lee, Chaur-Jeng Wang, Mechanical properties of gradient and multilayered TiAlSiN hard coatings, Thin Solid Films 517 (2009) 4934.

[2] S.H. Tsai, J.G. Duh, Microstructure and mechanical properties of CrAlN/SiNx nanostructure multilayered coatings, Thin Solid Films 518 (2009) 1480.

[3] P. Wiecinski, J. Smolik, H. Garbacz, K.J. Kurzydlowski, Microstructure and mechanical properties of nanostructure multilayer $\mathrm{CrN} / \mathrm{Cr}$ coatings on titanium alloy, Thin Solid Films 519 (2011) 4069

[4] V.Yu. Fominski, S.N. Grigoriev, J.P. Celis, R.I. Romanov, V.B. Oshurko, Structure and mechanical properties of $\mathrm{W}-\mathrm{Se}-\mathrm{C} /$ diamond-like carbon and $\mathrm{W}$-Se/diamond-like carbon bi-layer coatings prepared by pulsed laser deposition, Thin Solid Films 520 (2012) 6476.

[5] Zhou Bing, A.V. Rogachev, Zhubo Liu, Xiaohong Jian, Shen Ruiqi, A.S. Rudenkov, Structure and mechanical properties of diamond-like carbon films with copper functional layer by cathode arc evaporation, Surf. Coat. Technol. 208 (2012) 101

[6] J.B. Cai, X.L. Wang, W.Q. Bai, D.H. Wang, C.D. Gu, J.P. Tu, Microstructure, mechanical and tribological properties of a-C/a-C:Ti nanomultilayer film, Surf. Coat. Technol. 232 (2013) 403.

[7] Yin-Yu. Chang, Wu. Chen-Jui, Mechanical properties and impact resistance of multilayered TiAlN/ZrN coatings, Surf. Coat. Technol. 231 (2013) 62.

[8] Yujuan Zhang, Yuhao Zhai, Fengji Li, Shengmao Zhang, Pingyu Zhang, Sam Zhang, Effect of microstructure and mechanical properties difference between sub-layers on the performance of alternate hard and soft diamond-like carbon multilayer films, Surf. Coat. Technol. 232 (2013) 575.

[9] N. Patel, S. Wang, A. Inspektor, P.A. Salvador, Secondary hardness enhancement in large period TiN/TaN superlattices, Surf. Coat. Technol. 254 (2014) 21.

[10] V.Zuerbig, J. Hees, W. Pletschen, R.E. Sah, M. Wolfer, L. Kirste, N. Heidrich, C.E. Nebel, O. Ambacher, V. Lebedev, Elastic properties of ultrathin diamond/AlN membranes, Thin Solid Films 558 (2014) 267.

[11] M. Parlinska-Wojtan, S. Meier, J. Patscheider, Transmission electron microscopy characterization of TiN/SiNx multilayered coatings plastically deformed by nanoindentation, Thin Solid Films 518 (2010) 4890.

[12] P.L. Sun, J.P. Chu, T.Y. Lin, Y.L. Shen, N. Chawla, Characterization of nanoindentation damage in metal/ceramic multilayered films by transmission electron microscopy (TEM), Mater. Sci. Eng. A 527 (2010) 2985

[13] P. Wieciński, J. Smolik, H. Garbacz, KJ. Kurzydłowski, Failure and deformation mechanisms during indentation in nanostructured $\mathrm{Cr} / \mathrm{CrN}$ multilayer coatings, Surf. Coat. Technol. 240 (2014) 23.

[14] D.G. Liu, J.P. Tu, C.D. Gu, R. Chen, C.F. Hong, Tribological and mechanical behaviors of TiN/CNx multilayer films deposited by magnetron sputtering, Thin Solid Films 519 (2011) 4842.

[15] T. Mori, M. Noborisaka, T. Watanabe, T. Suzuki, Oxidation resistance and hardness of TiAlSiN/CrAlYN multilayer films deposited by the arc ion plating method, Surf. Coat. Technol. 213 (2012) 216

[16] M. Schlögl, J. Paulitsch, J. Keckes, P.H. Mayrhofer, Influence of AIN layers on mechanical properties and thermal stability of $\mathrm{Cr}$-based nitride coatings, Thin Solid Films 531 (2013) 113.

[17] M. Schlögl, B. Mayer, J. Paulitsch, P.H. Mayrhofer, Influence of AIN layers on mechanical properties and thermal stability of $\mathrm{Cr}$-based nitride coatings, Thin Solid Films 545 (2013) 375. 
[18] Y.D. Sun, D.J. Li, C.K. Gao, N. Wang, J.Y. Yan, L. Dong, M. Cao, X.Y. Deng, H.Q. Gu, R.X Wan, The effect of annealing on hardness, residual stress, and fracture resistance determined by modulation ratios of $\mathrm{TiB}_{2}$ /TiAlN multilayers, Surf. Coat. Technol. 228 (2013) S385.

[19] Mao Wen, Hao Huang, Kan Zhang, Qingnan Meng, Xin Li, Lingwei Kong, Chaoquan Hu, Weitao Zheng, The AlN layer thickness dependent coherent epitaxial growth, stress and hardness in NbN/AlN nanostructured multilayer films, Surf. Coat. Technol. 235 (2013) 367.

[20] M. Azadi, A. Sabour Rouhaghdam, S. Ahangarani, H.H. Mofidi, Mechanical behavior of TiN/TiC multilayer coatings fabricated by plasma assisted chemical vapor deposition on AISI H13 hot work tool steel, Surf. Coat. Technol. 245 (2014) 156.

[21] W.Q. Bai, J.B. Cai, X.L. Wang, D.H. Wang, C.D. Gu, J.P. Tu, Mechanical and tribological properties of a-C/a-C:Ti multilayer films with various bilayer periods, Thin Solid Films 558 (2014) 176

[22] R.D. Jamison, Y.-L. Shen, Indentation behavior of multilayered thin films: effects of layer undulation, Thin Solid Films 570 (2014) 235.

[23] S. Lotfian, C. Mayer, N. Chawla, J. Llorca, A. Misra, J.K. Baldwind, J.M. MolinaAldareguía, Effect of layer thickness on the high temperature mechanical properties of Al/SiC nanolaminates, Thin Solid Films 571 (2014) 260.

[24] M.A. Monclús, M. Karlik, M. Callisti, E. Frutos, J. LLorca, T. Polcar, J.M. MolinaAldareguía, Microstructure and mechanical properties of physical vapor deposited $\mathrm{Cu} / \mathrm{W}$ nanoscale multilayers: influence of layer thickness and temperature, Thin Solid Films 571 (2014) 275.

[25] J.J. Roa, E. Jiménez-Piqué, R. Martínez, G. Ramírez, J.M. Tarragó, R. Rodríguez, L. Llanes, Contact damage and fracture micromechanisms of multilayered $\mathrm{TiN} / \mathrm{CrN}$ coatings at micro- and nano-length scales, Thin Solid Films 571 (2014) 308.

[26] R.L. Schoeppner, N. Abdolrahim, I. Salehinia, H.M. Zbib, D.F. Bahr, Elevated temperature dependence of hardness in tri-metallic nano-scale metallic multilayer systems, Thin Solid Films 571 (2014) 247.

[27] C. Tritremmel, R. Daniel, H. Rudigier, P. Polcik, C. Mitterer, Mechanical and tribological properties of Al-Ti-N/Al-Cr-B-N multilayer films synthesized by cathodic arc evaporation, Surf. Coat. Technol. 246 (2014) 57.

[28] N. Verma, V. Jayaram, Role of interface curvature on stress distribution under indentation for ZrN/Zr multilayer coating, Thin Solid Films 571 (2014) 283.

[29] Seung Min Han, Eric P. Guyer, William D. Nix, Extracting thin film hardness of extremely compliant films on stiff substrates, Thin Solid Films 519 (2011) 3221.

[30] A. López-Puerto, F. Avilés, F. Gamboa, A.I. Oliva, A vibrational approach to determine the elastic modulus of individual thin films in multilayers, Thin Solid Films 565 (2014) 228 .

[31] Wu Tang, Kewei Xu, Jian Lu, The mechanical properties and resistivity of $\mathrm{Au} / \mathrm{NiCr} / \mathrm{Ta}$ multi-layered films on Si-(111) substrate, Thin Solid Films 520 (2011) 824.

[32] H. Chien, C. Diaz-Jimenez, G.S. Rohrer, Z. Ban, P. Prichard, Y. Liu, The influence of residual thermal stresses on the mechanical properties of multilayer $\alpha-\mathrm{Al}_{2} \mathrm{O}_{3} /$ $\mathrm{TiC}_{\mathrm{x}} \mathrm{N}_{1-\mathrm{x}}$ coatings on WC/Co cutting tools, Surf. Coat. Technol. 215 (2013) 119.

[33] J.M. Lackner, W. Waldhauser, B. Major, L. Major, M. Kot, Plastic deformation in nanoscale multilayer materials - a biomimetic approach based on nacre, Thin Solid Films 534 (2013) 417.

[34] S.J. Bull, Size effects in the mechanical response of nanoscale multilayer coatings on glass, Thin Solid Films (2014), Thin Solid Films 571 (2014) 290.

[35] S. Kataria, S. Goyal, S. Dash, R. Sandhya, M.D. Mathew, A.K. Tyagi, Evaluation of nanomechanical properties of hard coatings on a soft substrate, Thin Solid Films 522 (2012) 297.

[36] B. Jönsson, S. Hogmark, Hardness measurements of thin films, Thin Solid Films 114 (1984) 257.

[37] P.J. Burnett, D.S. Rickerby, The mechanical properties of wear-resistant coatings I: modelling of hardness behaviour, Thin Solid Films 148 (1987) 41.

[38] D. Chicot, J. Lesage, Absolute hardness of films and coatings, Thin Solid Films 254 (1995) 123.
[39] A.M. Korsunsky, M.R. McGurk, S.J. Bull, T.F. Page, On the hardness of coated systems, Surf. Coat. Technol. 99 (1998) 171

[40] J.R. Tuck, A.M. Korsunsky, R.I. Davidson, S.J. Bull, D.M. Elliott, Modelling of the hardness of electroplated nickel coatings on copper substrates, Surf. Coat. Technol. 127 (2000) 1.

[41] J.R. Tuck, A.M. Korsunsky, D.G. Bhat, S.J. Bull, Indentation hardness evaluation of cathodic arc deposited thin hard coatings, Surf. Coat. Technol. 139 (2001) 63.

[42] E.S. Puchi-Cabrera, A new model for the computation of the composite hardness of coated systems, Surf. Coat. Technol. 160 (2002) 177.

[43] E.S. Puchi-Cabrera, Computation of composite hardness of coated systems, Surf. Eng. 20 (5) (2004) 332

[44] S.J. Bull, Interface engineering and graded films: structure and characterization, J. Vac. Sci. Technol. A 19 (2001) 1404. http://dx.doi.org/10.1116/1.1355359.

[45] K. Rahmoun, A. Iost, V. Keryvin, G. Guillemot, N.E. Chabane Sari, A multilayer model for describing hardness variations of aged porous silicon low-dielectric-constant thin films, Thin Solid Films 518 (2009) 213.

[46] D. Beegan, M.T. Laugier, Application of composite hardness models to copper thin film hardness measurement, Surf. Coat. Technol. 199 (2005) 32.

[47] D. Beegan, S. Chowdhury, M.T. Laugier, Modification of composite hardness models to incorporate indentation size effects in thin films, Thin Solid Films 516 (2008) 3813.

[48] M. Jarratt, J. Stallard, N.M. Renevier, D.G. Teer, An improved diamond-like carbon coating with exceptional wear properties, Diam. Relat. Mater. 12 (2003) 1003.

[49] M.H. Staia, E.S. Puchi Cabrera, A. Iost, A. Zairi, S. Belayer, A. Van Gorp, Tribological response of AA 2024-T3 aluminium alloy coated with a DLC duplex coating, Tribol. Int. 85 (2015) 74-87.

[50] W.C. Oliver, G.M. Pharr, Measurement of hardness and elastic modulus by instrumented indentation: advances in understanding and refinements to methodology, J. Mater. Res. 19 (2004) 3.

[51] A. Iost, G. Guillemot, Y. Rudermann, M. Bigerelle, A comparison of models for predicting the true hardness of thin films, Thin Solid Films 524 (2012) 229.

[52] Norme Européenne NF EN 14577-4, Matériaux Métalliques: Essai de pénétration instrumenté pour la détermination de la dureté et des paramètres de matériaux, Partie 4: Méthode d'essai pour les revêtements métalliques et non métalliques (2007) Indice de classement: A 03-155-4, ICS: 77.040.10, 1er tirage 2007-08-P, 130.

[53] T. Michler, M. Grischke, I. Traus, K. Bewilogua, H. Dimigen, Mechanical properties of DLC films prepared by bipolar pulsed DC PACVD, Diam. Relat. Mater. 7 (1998) 1333.

[54] H.X. Li, T. Xu, J.M. Chen, H.D. Zhou, H.W. Liu, The effect of applied dc bias voltage on the properties of a-C:H films prepared in a dual dc-rf plasma system, Appl. Surf. Sci. 227 (2004) 364.

[55] K. Yamamoto, K. Matsukado, Effect of hydrogenated DLC coating hardness on the tribological properties under water lubrication, Tribol. Int. 39 (2006) 1609.

[56] J. Luo, R. Stevens, Porosity-dependence of elastic moduli and hardness of 3Y-TZP Ceramics, Ceram. Int. 25 (1999) 281.

[57] J. Adachi, K. Kurosaki, M. Uno, S. Yamanaka, Porosity influence on the mechanical properties of polycrystalline zirconium nitride ceramics, J. Nucl. Mater. 358 (2006) 106.

[58] Yefei Li, Yimin Gao, Bing Xiao, Ting Min, Ying Yang, Shengqiang Ma, Dawei Yi, The electronic, mechanical properties and theoretical hardness of chromium carbides by first-principles calculations, J. Alloys Compd. 509 (2011) 5242.

[59] K. Hirota, K. Mitani, M. Yoshinaka, O. Yamaguchi, Simultaneous synthesis and consolidation of chromium carbides $\left(\mathrm{Cr}_{3} \mathrm{C}_{2}, \mathrm{Cr}_{7} \mathrm{C}_{3}\right.$ and $\left.\mathrm{Cr}_{23} \mathrm{C}_{6}\right)$ by pulsed electriccurrent pressure sintering, Mater. Sci. Eng. A 399 (2005) 154. 